\title{
Comparación de la Muestra Salival y de Nasofaringe en la Detección de SARS-CoV-2 mediante RT-PCR
}

\author{
Comparison Between Saliva and Nasopharyngeal \\ Sample in Detection of SARS-CoV-2 by RT-PCR
}

Fernando Parada Fernández'; Diego Fonseca Escobar;
Melissa Carvajal Guzmán² \& Cristóbal Sepúlveda Verdugo ${ }^{3}$

PARADA, F. F.; FONSECA, E. D.; CARVAJAL, G. M. \& SEPÚLVEDA, V. C. Comparación de la muestra salival y de nasofaringe en la detección de SARS-CoV-2 mediante RT-PCR. Int. J. Odontostomat., 14(4):540-543, 2020.

RESUMEN: El coronavirus tipo 2, SARS-CoV-2, que causa la enfermedad denominada por la OMS como COVID19 , se ha expandido provocando una pandemia desde 2019, sin cura hasta la fecha. El mecanismo de transmisión del SARS-CoV-2 entre humanos es mediante las secreciones generadas durante la respiración y estornudos, presentándose con un período de incubación desde 1 a 14 días. Se describen fiebre, tos y astenia como los síntomas más habituales. El diagnóstico definitivo se logra a través de la correlación entre la presentación clínica y exámenes complementarios, pero en la actualidad, el método de muestreo de preferencia para el diagnóstico de SARS-CoV-2 es mediante una muestra de nasofaringe, en donde se analiza la presencia de material genético viral por medio de RT-PCR. Debido a las complicaciones en la obtención de la muestra, tanto para el personal sanitario como para el paciente, se ha implementado la muestra de saliva con finalidad diagnóstica, como un método que proporciona una detección rápida, simple y no invasiva de la infección viral. Esta alternativa diagnóstica podría entregar información respecto a la patogenia de la enfermedad, permitiendo el manejo y control de pacientes positivos. El siguiente artículo, tiene por objetivo realizar una comparación entre las tomas de muestra de saliva y de nasofaringe para el diagnóstico de SARS-CoV-2, mediante la prueba de reacción en cadena de la polimerasa con transcriptasa inversa (RT-PCR).

PALABRAS CLAVE: saliva; RT-PCR, muestra nasofaríngea, SARS-CoV-2; Covid-19.

\section{INTRODUCCIÓN}

El objetivo de esta revisión fue realizar una comparación entre las tomas de muestra de saliva y de nasofaringe para el diagnóstico de SARS-CoV-2 mediante la prueba de reacción en cadena de la polimerasa con transcriptasa inversa (RT-PCR).

EI SARS-CoV-2 es un tipo de virus de la familia Coronaviridae, subfamilia Orthocoronavirinae, del género Betacoronavirus, causante de la enfermedad por coronavirus (COVID-19) cuya expansión mundial ha provocado la pandemia de 2019 hasta la fecha, la cual lleva más de 8 millones de casos confirmados y 450.000 muertos notificados hasta junio del 2020. En la actualidad, se han descubierto siete coronavirus relacionados con enfermedades huma- nas, siendo el SARS-CoV-2 el séptimo, reportado en Wuhan a finales del año 2019 (Singhal et al., 2020).

Este virus presenta un tamaño aproximado que varía entre 60 a $140 \mathrm{~nm}$ de diámetro. Su genoma se encuentra formado por una sola cadena de ARN monocatenario positiva, cuya secuencia es de aproximadamente treinta mil nucleótidos de longitud. Consta de cuatro genes, que codifican para las proteínas estructurales S (homotrímero de glicoproteína), E (proteína de la envoltura), M (proteína de la matriz) y $\mathrm{N}$ (fosfoproteína de la nucleocápside), además de presentar un marco abierto de lectura (ORFs) que codifican proteínas no estructurales (Guo et al., 2020).

\footnotetext{
${ }^{1}$ Cirujano dentista, Universidad Andrés Bello, Santiago, Chile.

${ }^{2}$ Cirujano dentista. Residente de Cirugía Maxilofacial, Facultad de Medicina Clínica Alemana - Universidad del Desarrollo, Santiago de Chile.

${ }^{3}$ Cirujano dentista, Pasante Servicio Cirugía Maxilofacial, Hospital San Juan de Dios, Santiago de Chile.
} 


\section{Epidemiología y Patogénesis}

Respecto al mecanismo de transmisión del SARS-CoV-2 entre humanos, se produce mediante secreciones del tracto respiratorio generadas durante la respiración, estornudos y el habla; no se ha demostrado una predilección por edad y/o género (Wujtewicz et al., 2020). Se señala que el período de incubación y presentación de signos y síntomas de COVID-19 fluctúa entre 1 a 14 días luego del contagio, según la Organización Mundial de la Salud (OMS) (OMS, 2020). Diversos estudios han identificado que las mucosas nasal y laríngea son utilizadas como vías de ingreso del virus hacia los pulmones, donde una vez en la sangre, la glicoproteína $S$ (ubicado en su envoltura) interactúa con el receptor de la enzima convertidora de angiotensina 2 (ECA2), una exopeptidasa de membrana ubicada en las células de la mucosa respiratoria, riñón, pulmones, corazón y sistema gastro-intestinal, generando un desequilibrio del sistema reninaangiotensina-aldosterona (Wujtewicz et al.).

\section{Signos y síntomas}

Dentro de los síntomas que pueden presentar los pacientes contagiados, se describen, fiebre $(88,7 \%)$, tos $(67,8 \%)$, astenia $(38,1 \%)$, esputo $(33,4$ $\%)$, disnea $(18,6 \%)$, odinofagia $(13,9 \%)$, cefalea $(13,6$ $\%)$, diarrea $(3,8 \%)$ y emesis ( $5 \%)$. Cabe señalar que entre el 40 a $50 \%$ de los contagiados, presentan manifestaciones clínicas (Adhikari et al., 2020).

\section{Diagnóstico y métodos diagnósticos}

El diagnóstico definitivo se logra a través de la correlación entre la presentación clínica y exámenes complementarios, como es el uso de pruebas moleculares específicas (Lin et al., 2020).

Respecto a los exámenes complementarios utilizados se describen la radiografía de tórax, observándose un infiltrado bilateral y la tomografía computarizada con patrón en vidrio esmerilado en pacientes con sintomatología asociada (Shi et al., 2020). Sobre los exámenes de laboratorio, los pacientes pueden presentar leucopenia y linfocitopenia. Además, los pacientes graves presentan altos niveles séricos de urea y creatinina, mientras que los linfocitos siguen disminuyendo (Xia et al., 2020).

La OMS ha publicado varios protocolos para el diagnóstico de COVID-19, donde la prueba de elección es la retrotranscripción seguida de reacción en cadena de la polimerasa cuantitativa (RT-PCR), que se realiza mediante la obtención de una muestra respiratoria obtenida con un hisopo nasofaríngeo, esputo, aspirados endotraqueales y lavado broncoalveolar; el resultado puede estar en horas (Singhal et al.).

La RT-PCR, es una técnica de laboratorio, el cual consiste en amplificar una hebra de RNA mediante su retrotranscripción con el uso de una enzima llamada transcriptasa inversa, cuyo fin es la obtención de DNA complementario que posteriormente servirá para detectar la presencia del material genético viral. Cabe señalar que RT-PCR, presenta una gran especificidad, cercana al $100 \%$ y una sensibilidad variable, que depende de la zona y tipo de muestra obtenida del paciente enfermo, entre ellas el esputo con $89 \%$ de sensibilidad, nasal $73 \%$ y orofaringe $60 \%$ (Bachman et al., 2013).

En la actualidad el Gold Standard para el diagnóstico de COVID-19 es a través de muestras obtenidas por hisopos nasofaríngeos para RT-PCR, pero este procedimiento no está exento de complicaciones, tanto para el personal sanitario, como para los pacientes. (To et al., 2020a). Es por ello, que otras formas de obtención de las muestras se hacen necesarias, y la saliva se presenta como una posible biomuestra.

La saliva tiene un rol importante en la transmisión viral a través de pequeñas gotas, y, respecto a la procedencia viral, se describen como mínimo 3 vías. La más evidente es a través del flujo establecido entre la cavidad oral y el tracto respiratorio inferior y superior, mediante el fluido crevicular gingival (por la presencia viral en la sangre) y a través de las glándulas salivales menores y mayores (Sabino-Silva et al., 2020).

Las glándulas salivales presentan una alta expresión de receptores ECA2, esto las transforma en parte de la patogenia de la enfermedad. (Liu et al., 2011; Xu, et al., 2020). Un estudio en animales ha demostrado la infección del epitelio de los ductos de las glándulas salivares menores en infecciones por SARSCoV-1 (Liu et al.), lo que fundamenta la posible infección por parte de SARS-CoV-2. Por otra parte, se describió la expresión de ECA2 en el tejido oral y en la mucosa gingival, además de una alta expresión en las células epiteliales de la lengua, por lo que la invasión oral podría ser teóricamente posible (Xu et al.).

\section{Recolección de muestras mediante saliva}

La toma de muestra de saliva presenta ciertas ventajas como lo son una obtención no invasiva, me- 
PARADA, F. F.; FONSECA, E. D.; CARVAJAL, G. M. \& SEPÚLVEDA, V. C. Comparación de la muestra salival y de nasofaringe en la detección de SARS-CoV-2 mediante RTPCR. Int. J. Odontostomat., 14(4):540-543, 2020.

nor riesgo de contagio para el personal sanitario, la posibilidad de realizar una auto-muestra, menor riesgo de hemorragia para pacientes con trastornos en la coagulación, entre otros (Ceron et al., 2020; Melián et al., 2020).

\section{Uso de saliva en la detección viral mediante RT- PCR}

Un estudio realizado por Kim et al. en 2016, en donde participaron 236 pacientes con historial de tos, esputo y rinorrea, se les tomaron muestras de nasofaringe (MNF) y saliva. Estas muestras fueron sometidas a RT-PCR en búsqueda de infecciones virales, donde las MNF lograron identificar 183 casos $(77,5 \%)$, mientras que de las muestras salivales identificaron 180 casos $(76,3 \%)$ y la diferencia entre ambas muestras no fue estadísticamente significativa ( $p$ $=0,766)$. En este mismo estudio se analizaron los tipos de virus encontrados, y de un total de 346 virus, 256 fueron identificados por MNF (73,4 \%) y $273(78,2$ $\%)$ por muestras salivales, sin presentar diferencias estadísticamente significativas ( $p=0,1574)$, concluyendo que las muestras de saliva permiten una evaluación fácil, con bajos costos, además de una tasa de detección general comparable a la de las MNF cuando se usó RT-PCR para la detección viral (Kim et al.).

\section{Evidencia del uso de saliva en la detección del SARS-CoV-2 mediante RT-PCR}

El estudio realizado en el Public Health Laboratory Services Branch en Hong Kong, tomó muestras salivales de 12 pacientes positivos a COVID19 , a las cuales se les realizó la prueba de RT-PCR. Estas muestras se recolectaron en una media de 2 días después de la hospitalización, en un rango de 0 a 7 días como máximo. Los resultados de las muestras de saliva detectaron a 11 pacientes positivos al SARSCoV-2 19 (91,7 \%) (To et al., 2020a).

Un estudio realizado en la universidad de Yale (Wyllie et al., 2020), en el cual se comparó la detección de SARS-COV-2 en MNF y de saliva, identificó que la saliva presenta una mayor sensibilidad de detección y consistencia durante el curso de la infección, sugiriendo que la saliva es un tipo de muestra que permite controlar los cambios en la titulación de SARSCoV-2 en el tiempo, con menores riesgos y costos, incluso para pacientes asintomáticos o presintomáticos. Reportaron asimismo que la titulación viral era significativamente más elevada ( 5 veces más alta) en las muestras salivales (Wyllie et al.).
Tal como lo planteó el estudio de la Universidad de Yale, Azzi et al. (2020) y colaboradores informaron de dos pacientes asintomáticos que fueron positivos a muestras salivales, mientras que negativo a MNF. Estos autores presentaron también (en el mismo estudio), un $100 \%$ de las muestras positivas al SARS-CoV-2 a través de la recolección de 25 muestras salivales de pacientes diagnosticados con el virus, en categorías de condición severa a muy severa de la enfermedad (Azzi et al.).

To et al. (2020a,b) analizaron 23 muestras salivales de pacientes ya diagnosticados mediante MNF, y obtuvieron una sensibilidad de $87 \%$ (20 pacientes positivos) para las muestras de saliva. Adicionalmente analizaron 33 muestras de pacientes sanos, los cuales en su totalidad fueron negativas para el virus.

Por otra parte, la U.S. Food and Drug Administration (FDA) autorizó a los investigadores de la Universidad de Rutgers la creación de una prueba de auto-muestra de saliva para la detección de SARSCoV-2, utilizando la saliva como una fuente viable para la detección de la infección. Este test aumentaría la cantidad de pruebas realizadas y eliminaría el requisito de asistir a centros hospitalarios para su recolección (FDA), 2020; Rutgers University, 2020).

\section{CONCLUSIÓN}

Las muestras de saliva proporcionan una opción similar a las muestras nasofaríngeas para la detección del SARS-CoV-2, con una sensibilidad semejante en las pruebas de RT-PCR, pero con evidentes ventajas para las muestras salivales, debido a la simplificación en la toma de muestras, posibilidades de disminuir eventuales infecciones para el personal sanitario o para el paciente al tener que dirigirse a centros hospitalarios para su realización, además de la incomodidad percibida por el paciente al momento de su obtención. Aun así, es necesario realizar estudios con un mayor número de muestras para poder determinar realmente la eficiencia de la saliva como biomuestra para el COVID-19 utilizando RT-PCR.

PARADA, F. F.; FONSECA, E. D.; CARVAJAL, G. M. \& SEPÚLVEDA, V. C. Comparison between saliva and nasopharyngeal sample in detection of SARS-CoV-2 by RTPCR. Int. J. Odontostomat., 14(4):540-543, 2020.

SUMMARY: The type 2 coronavirus, SARS-CoV-2, named by the WHO like COVID-19, has expanded causing a 
pandemic since 2019 , with no cure to date. The mechanism of transmission of SARS-CoV-2 between humans is through secretions generated during breathing and sneezing, presenting with an incubation period range from 1 - 14 days. Fever, cough, and fatigue are described as the most common symptoms. The definitive diagnosis is achieved through the correlation between the clinical presentation and the complementary exams, but at present, the preferred sampling method for the diagnosis of SARS-CoV-2 is through a nasopharyngeal swab specimen, where it is analyzed the presence of viral genetic material by the $\mathrm{RT}-\mathrm{PCR}$. Due to the complications in obtaining the sample, both for health personnel and for the patient, the saliva sample has been implemented, as a method that provides rapid, simple and non-invasive detection of viral infection. This diagnostic alternative could provide information on the pathogenesis of the disease, the management and control of positive patients. The following article aims to make a comparison between the saliva and nasopharyngeal samples taken for the diagnosis of SARSCoV-2, using the reverse transcription polymerase chain reaction test (RT-PCR).

KEY WORDS: saliva; RT-PCR, nasopharyngeal swab, SARS-CoV-2; Covid-19.

\section{REFERENCIAS BIBLIOGRÁFICAS}

Adhikari, S. P.; Meng, S.; Wu, Y. J.; Mao, Y. P.; Ye, R. X.; Wang, Q. Z.; Sun, C.; Sylvia, S.; Rozelle, S.; Raat, H.; et al. Epidemiology, causes, clinical manifestation and diagnosis, prevention and control of coronavirus disease (COVID-19) during the early outbreak period: a scoping review. Infect. Dis. Poverty, 9:29, 2020.

Azzi, L.; Carcano, G.; Gianfagna, F.; Grossi, P.; Gasperina, D. D.; Genoni, A.;Fasano, M.; Sessa, F.; Tettamanti, L.; Carinci, F.; et al. Saliva is a reliable tool to detect SARS-CoV-2. J. Infect., 81(1):e45-e50, 2020.

Bachman, J. Chapter Two - Reverse-Transcription PCR (RT- PCR). In: Lorsch, J. (Ed.). Laboratory Methods in Enzymology. RNA. Amsterdam, Elsevier/Academic Press, 2013. pp.67-74.

Ceron, J. J.; Lamy, E.; Martinez-Subiela, S.; Lopez-Jornet, P.; CapelaSilva, F.; Eckersall, P. D. \& Tvarijonaviciute, A. Use of saliva for diagnosis and monitoring the SARS-CoV-2: a general perspective. J. Clin. Med., 9(5):1491, 2020.

Food and Drug Administration (FDA). Coronavirus (COVID-19) Update: FDA Authorizes First Diagnostic Test Using At-Home Collection of Saliva Specimens. Washington (D.C.), Food and Drug Administration, 2020. Disponible en: https://www.fda.gov/newsevents/press-announcements/coronavirus-covid-19-update-fdaauthorizes-first-diagnostic-test-using-home-collectionsaliva\#: :text=Today $\% 2$ C $\% 20$ the $\% 20$ U.S.\%20Food\%20and,samples $\%$ 20for\%20COVID\%2D19\%20testing.\&text=Once\%20patients\%20collect $\% 20$ their\%20saliva,a\%20sealed\%20package\%20for\%20testing.

Guo, Y. R.; Cao, Q. D.; Hong, Z. S.; Tan, Y. Y.; Chen, S. D.; Jin, H. J.; Tan, K. S.; Wang, D. Y. \& Yan, Y. The origin, transmission and clinical therapies on Coronavirus Disease 2019 (COVID19) outbreak - An update on the status. Mil. Med. Res., 7(1):11, 2020.

Kim, Y. G.; Yun, S. G.; Kim, M. Y.; Park, K.; Cho, C. H.; Yoon, S. Y.; Nam, M. H.; Lee, C. K.; Cho, Y. J. \& Lim, C. S. Comparison between saliva and nasopharyngeal swab specimens for detection of respiratory viruses by multiplex reverse transcription-PCR. J. Clin. Microbiol., 55(1):226-33, 2016.
Lin, L.; Lu, L.; Cao, W. \& Li, T. Hypothesis for potential pathogenesis of SARS-CoV-2 infection-a review of immune changes in patients with viral pneumonia. Emerg. Microbes Infect., 9(1):727-32, 2020.

Liu, L.; Wei, Q.; Alvarez, X.; Wang, H.; Du, Y.; Zhu, H.; Jiang, H.; Zhou, J.; Lam, P.; Zhang, L.; et al. Epithelial cells lining salivary gland ducts are early target cells of severe acute respiratory syndrome coronavirus infection in the upper respiratory tracts of rhesus macaques. J. Virol., 85(8):4025-30, 2011.

Melián, R. A.; Wallach, W. M.; Boin, B. C. \& Carrasco, S. R. Recommendations in the care of patients in maxillofacial surgery during the COVID-19 pandemic (SARS-CoV-2). Int. J. Odontostomat., 14(4):474-80, 2020.

Rutgers University. Rutgers Launches Genetic Testing Service for New Coronavirus. New Jersey, Rutgers University, 2020. Disponible en: https://www.rutgers.edu/news/rutgers-launchesgenetic-testing-service-new-coronavirus

Sabino-Silva, R.; Jardim, A. C. G. \& Siqueira, W. L. Coronavirus COVID-19 impacts to dentistry and potential salivary diagnosis. Clin. Oral Investig., 24:1619-21, 2020.

Shi, H.; Han, X.; Jiang, N.; Cao, Y.; Alwalid, O.; Gu, J.; Fan, Y. \& Zheng, C. Radiological findings from 81 patients with COVID19 pneumonia in Wuhan, China: a descriptive study. Lancet Infect. Dis., 20(4):425-34, 2020.

Singhal, T. A review of Coronavirus Disease-2019 (COVID-19). Indian J. Pediatr., 87:281-6, 2020.

To, K. K. W.; Tsang, O. T. Y.; Yip, C. C. Y.; Chan, K. H.; Wu, T. C.; Chan, J. M. C.; Leung, W. S.; Chik, T. S. H.; Choi, C. Y. C.; Kandamby, D. H.; et al. Consistent detection of 2019 novel Coronavirus in saliva. Clin. Infect. Dis., ciaa149, 2020a.

To, K. K. W.; Tsang, O. T. Y.; Leung, W. S.; Tam, A. R.; Wu, T. C.; Lung, D. C.; Yip, C. C. Y.; Cai, J. P.; Chan, J. M. M.; Chik, T. S. $\mathrm{H}$.; et al. Temporal profiles of viral load in posterior oropharyngeal saliva samples and serum antibody responses during infection by SARS-CoV-2: an observational cohort study. Lancet Infect. Dis., 20(5):565-74, 2020b.

Wujtewicz, M.; Dylczyk-Sommer, A.; Aszkielowicz, A.; Zdanowski, S.; Piwowarczyk, S. \& Owczuk, R. COVID-19 - What should anaethesiologists and intensivists know about it? Anaesthesiol. Intensive Ther., 52(1):34-41, 2020.

Wyllie, A. L.; Fournier, J.; Casanovas-Massana, A.; Campbell, M.; Tokuyama, M.; Vijayakumar, P.; Geng, B.; Muenker, M. C.; Moore, A. J.; Vogels, C. B. F.; et al. Saliva is more sensitive for SARS-CoV-2 detection in COVID-19 patients than nasopharyngeal swabs. MedRxiv, 2020. Pre-Print. DOI: https:/ /www.doi.org/10.1101/2020.04.16.20067835

Xia, W.; Shao, J.; Guo, Y.; Peng, X.; Li, Z. \& Hu, D. Clinical and CT features in pediatric patients with COVID-19 infection: Different points from adults. Pediatr. Pulmonol., 55(5):1169-74, 2020.

Xu, J.; Li, Y.; Gan, F.; Du, Y. \& Yao, Y. Salivary glands: potential reservoirs for COVID-19 asymptomatic infection. J. Dent. Res., 2020. DOI: https://www.doi.org/10.1177/0022034520918518

Dirección para correspondencia:

Fernando Parada Fernández

Universidad Andrés Bello

Santiago - CHILE

Email: fdo.parada.f@gmail.com
Recibido : 17-06-2020 Aceptado: 20-06-2020 